\title{
Síndromes compresivos vasculares: un desafío diagnóstico
}

\section{Vascular Compressive Syndromes: A Challenge Diagnosis}

\author{
Jesús Sanabria ${ }^{1}$ Andrea Zabala ${ }^{1}$ Vanesa DiCaro ${ }^{1}$ Marcelo Pietrani ${ }^{1}$ Martín Rabellino ${ }^{1}$ \\ ${ }^{1}$ Servicio de Diagnóstico por Imágenes, Hospital Italiano de Buenos \\ Aires, Ciudad Autónoma de Buenos Aires, Argentina \\ Rev Argent Radiol 2019;83:160-169. \\ Address for correspondence Jesús Sanabria, MD, Avenida Belgrano \\ 4202, Ciudad Autónoma de Buenos Aires, Argentina \\ (e-mail: jsanabria803@gmail.com).
}

\section{Resumen \\ Palabras clave \\ - angiografía por tomografía computarizada \\ - angiografía por resonancia magnética \\ - síndrome de May- Thurner \\ - síndrome renal de nutcracker \\ - síndrome de opérculo torácico}

Los síndromes de compresión vascular constituyen un grupo de patologías poco frecuentes con prevalencia incierta, no solo por el desconocimiento que se tiene de estos, sino también por su presentación clínica inespecífica. Eso conlleva a que sean infradiagnosticados o detectados en etapas tardías, con secuelas a largo plazo.

Su fisiopatología y clínica dependen del tipo de vaso comprometido, el sitio anatómico afectado y la causa subyacente que lo esté produciendo.

La anamnesis, el examen físico dirigido y el uso de métodos complementarios como la ultrasonografía Doppler y la angiografía por tomografía computarizada (ATC) o angiografía por resonancia magnética (ARM), son herramientas vitales para su correcto diagnóstico, planificación terapéutica y seguimiento.

\footnotetext{
Abstract

Keywords

- computed tomography angiography

- magnetic resonance angiography

- may-thurner syndrome

- renal nutcracker syndrome

- thoracic outlet syndrome
}

\begin{abstract}
Vascular compression syndromes constitute a group of rare pathologies with uncertain prevalence not only because of their unawareness, but also for its nonspecific clinical presentation. This leads to their underdiagnosis, or detection in late stages with longterm sequelae.

Its pathophysiology and presentation depends on the type of vessel involved, the affected anatomical site and the underlying cause producing it.

Clinical history, physical examination and use of complementary methods such as Doppler ultrasonography, Computed Tomography Angiography (CTA) or Magnetic Resonance Angiography (MRA), are essential tools for its proper diagnosis, therapeutic planning and follow-up.
\end{abstract}

\section{Introducción}

Los síndromes de compresión vascular se definen como una entidad causada por el atrapamiento de los vasos sanguíneos (arteria o vena), con una superficie rígida o semirrígida en un espacio anatómico confinado. El mismo afecta aproximadamente a menos del $1 \%$ de la población general. ${ }^{1}$ Existe un espectro muy grande de síndromes, divididos received

March 19, 2019

accepted

September 12, 2019
DOI https://doi.org/

$10.1055 / \mathrm{s}-0039-1698813$.

ISSN 1852-9992.
Copyright ( 2 2019, Sociedad Argentina de Radiología. Publicado por Thieme Revinter Publicações Ltda., Rio de Janeiro, Brazil. Todos los derechos reservados.

\section{License terms}

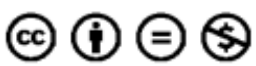


principalmente de acuerdo a si el compromiso es arterial, venoso o mixto. Entre los más representativos se incluyen el síndrome de May-Thurner, nutcracker y opérculo torácico. La fisiopatología y clínica de cada síndrome depende del tipo de vaso comprometido, el sitio anatómico afectado y la causa subyacente que lo esté produciendo. ${ }^{1,2}$

El diagnóstico se basa en el resultado de la evaluación clínica, las maniobras dinámicas al examen físico y el uso de métodos de imágenes. Como primer estudio, se tiene la ultrasonografía Doppler, la cual ha adquirido mayor uso en los últimos tiempos dando información importante para el manejo inicial. Por otro lado, la angiografía por tomografía computarizada (ATC) sigue siendo el estudio de elección para el diagnóstico de esas patologías debido a su alta sensibilidad, fácil accesibilidad y alto rédito diagnóstico. La angiografía por resonancia magnética (ARM) es otro método de gran utilidad, ya que cuenta con una mayor resolución tisular y permite la cuantificación de la magnitud y dirección del flujo sanguíneo. ${ }^{2}$

El propósito de este estudio es describir los hallazgos imagenológicos y su correlación con la literatura existente de una serie de casos de síndromes compresivos vasculares frecuentes y representativos, vistos en el servicio de imágenes de nuestra institución.

\section{Sindrome de May-Thurner}

El síndrome de May-Thurner, o mejor conocido como síndrome compresivo de la vena ilíaca, es una patología que consiste en la compresión de la vena ilíaca común izquierda (VICI) entre la columna lumbar baja y la arteria ilíaca común derecha (AICD) ( - Fig. 1). ${ }^{3}$ La incidencia exacta es desconocida, debido a que la compresión de la vena es una variante anatómica infradiagnosticada y se presenta de manera asintomática en la mayoría de los casos, sin requerir tratamiento. ${ }^{4}$ Entre los factores de riesgo que predisponen esa entidad, se encuentran el sexo femenino, el embarazo, especialmente en el postparto, anticonceptivos orales y la escoliosis. $^{5-7}$

Los síntomas son variados y dependen del tiempo de evolución del cuadro clínico. Generalmente afecta a mujeres con signos de trombosis venosa profunda (TVP) unilateral, asociado o no a la circulación colateral. En estadios más avanzados, puede presentarse con claudicación y/o flegmasía cerúlea. $^{8}$

Posterior a la evaluación clínica, los estudios por imágenes son esenciales en el diagnóstico de esos pacientes, el primer estudio recomendado para su evaluación es la ultrasonografía Doppler color, por ser un método no invasivo y de fácil acceso. Los principales hallazgos en ese método son la insuficiencia venosa y TVP iliofemoral (-Fig. 2). Las principales limitaciones son la dificultad para encontrar anormalidades en las venas ilíacas debido a su localización profunda, no evidenciándose en un $20 \%$ de los casos, y la difícil visualización del sitio de compresión. $^{9}$

Como métodos de elección se encuentran la ATCy ARM, que tienen una mayor precisión diagnóstica. Los hallazgos más característicos son la visualización de la compresión de la VICI, signos de trombosis aguda/crónica, la extensión de la misma y el desarrollo de vasos colaterales. La ATC posee una sensibilidad del $90 \%$ y una especificidad cercana al 100\% para el diagnóstico, aportando además información útil para el manejo endovascular y la evaluación de la permeabilidad del stent posterior a la intervención ( - Fig. 3). La ARM cuenta con la ventaja adicional de ser un estudio no invasivo, el cual no requiere uso de medios de contraste endovenoso, y la posibilidad de cuantificar la magnitud y el grado del flujo venoso colateral ( - Fig. 4). En su contra se tiene el alto costo, menor accesibilidad y menor calidad de las imágenes vasculares por encima de las bifurcaciones debido al flujo no laminar. ${ }^{9-11}$

Respecto al tratamiento, los pacientes que se encuentran asintomáticos y sin trombosis venosa profunda se benefician de un manejo conservador (medias de compresión). Cuando
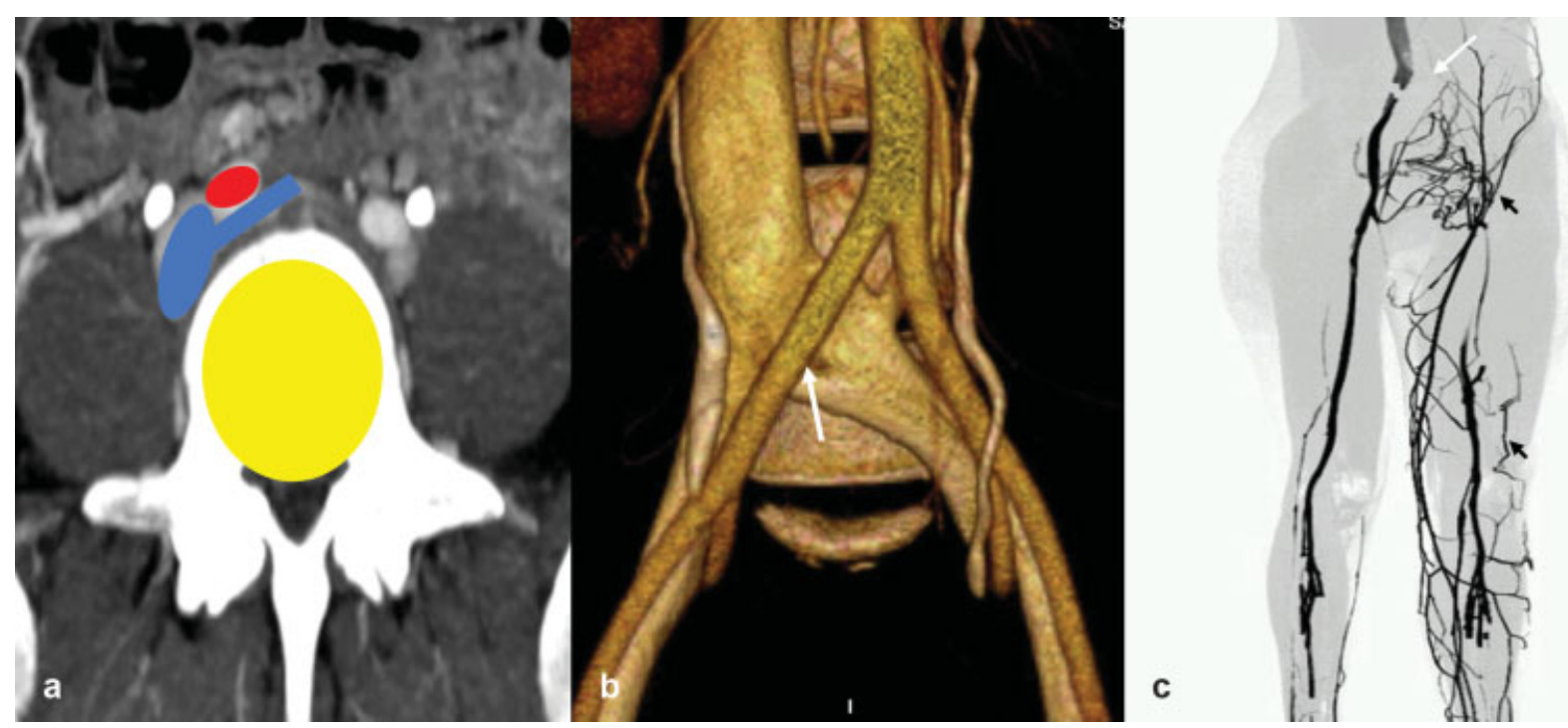

Fig. 1 (a) ATC de abdomen en corte axial con visualización de la compresión de la VICI (azul) entre la columna lumbar baja (amarillo) y la arteria ilíaca común derecha (rojo). (b) Reconstrucción 3D con evidencia de dicha compresión (flecha). (c) Flebografía de miembros inferiores con evidencia de ausencia de flujo de $\mathrm{VICl}$ (flecha blanca) con desarrollo de colaterales (flechas negras). Hallazgos sugestivos de síndrome de May-Thurner. 

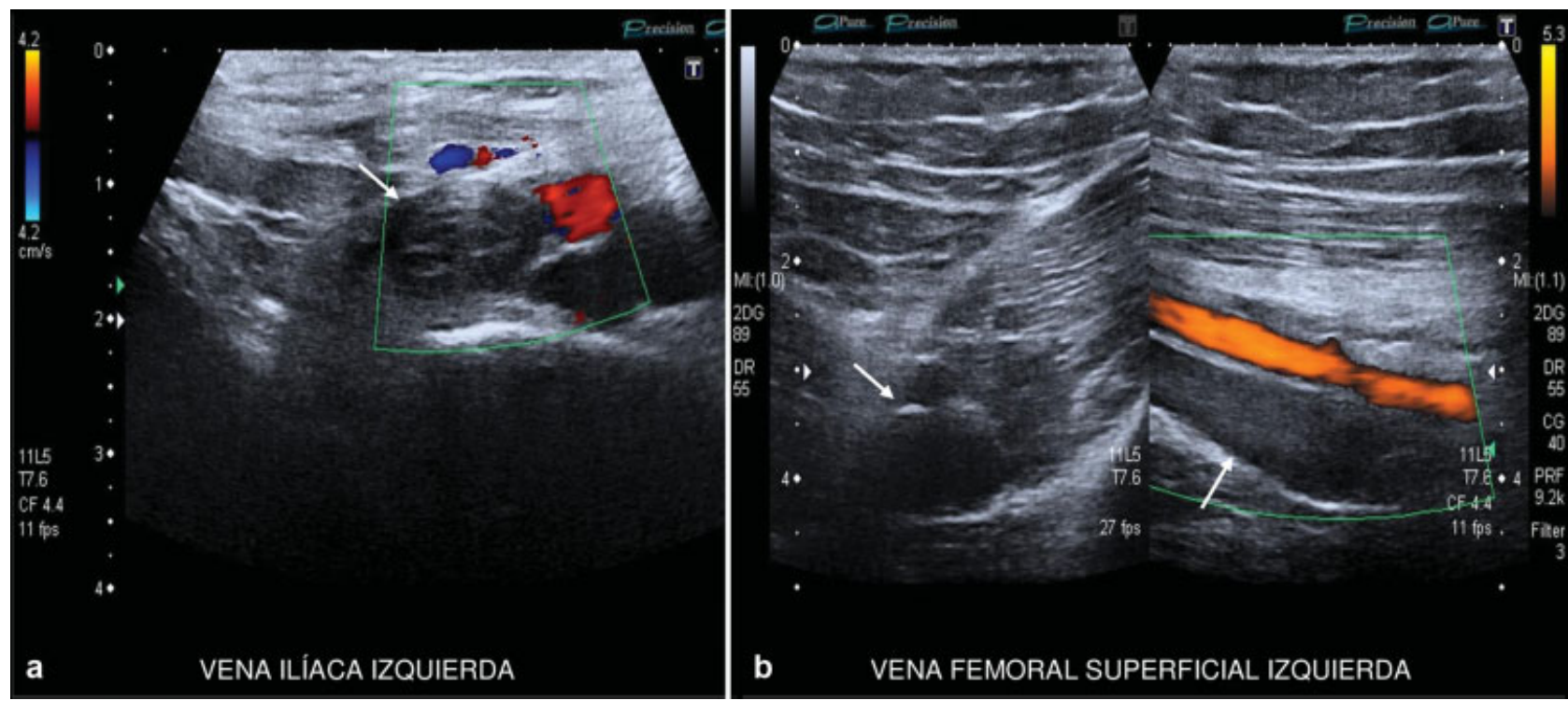

Fig. 2 Paciente femenina de 39 años en estudio por edema en miembros inferiores, se le realiza ultrasonografía Doppler venoso de miembros inferiores. (a) Corte transversal donde se evidencia dilatación de la vena ilíaca izquierda (flecha), la misma con contenido ecogénico en su interior compatible con trombosis venosa aguda. (b) Muestra en cortes transversal y longitudinal respectivamente una marcada dilatación del diámetro de la vena femoral superficial izquierda con contenido ecogénico en su interior (flechas), compatible con trombosis venosa aguda.
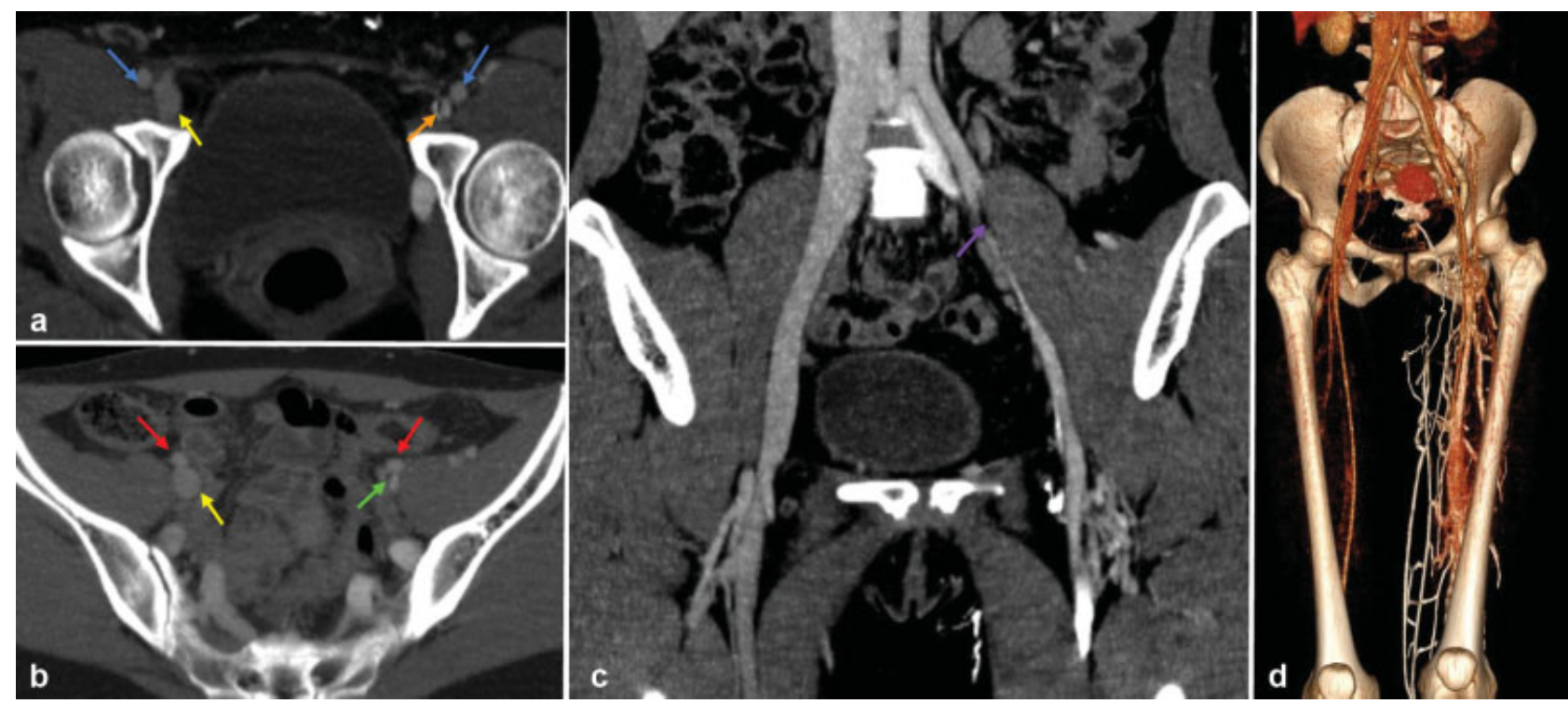

Fig. 3 Imágenes de ATC con reconstrucciones MIP y 3D. (a) y (b) Corte axial y (c) corte coronal. Se evidencia oclusión de la vena femoral común izquierda (flecha naranja). Reducción de calibre de la vena ilíaca primitiva izquierda (flecha verde) y oclusión de la vena iliaca externa izquierda (flecha morada). Arteria iliaca externa (flechas rojas), arteria femoral común (flechas azules), vena femoral común derecha (flecha amarilla). (d) Reconstrucción 3D, en la que se aprecia importante circulación colateral en relación a la trombosis crónica de la vena iliaca externa y femoral común homolateral.

genera síntomas o un cuadro de TVP, se requiere de un manejo invasivo para el control de la sintomatología y de la causa subyacente. El manejo de elección es la trombólisis farmacológica guiada por catéter endovascular y la trombectomía mecánica seguida de stent auto-expandible (-Fig. 5). ${ }^{11}$

\section{Sindrome de nutcracker}

El fenómeno de nutcracker o “cascanueces" se define como la compresión de la vena renal izquierda (VRI) entre la aorta abdominal y la arteria mesentérica superior (AMS) (nutcracker anterior). Existe una variante conocida como nutcracker posterior, en la cual la VRI se comprime entre la aorta abdominal y la columna vertebral, usualmente predispuesto por una variante retro-aórtica o circumaórtica de la VRI, siendo menos frecuente. Cuando cualquiera de esas dos entidades presenta sintomatología, se denomina Síndrome de nutcracker (-Fig. 6). ${ }^{12,13} \mathrm{Su}$ epidemiología, al igual que los demás síndromes vasculares, es desconocida debido a que en la mayoría de los casos se presentan de forma asintomática. ${ }^{13}$ 


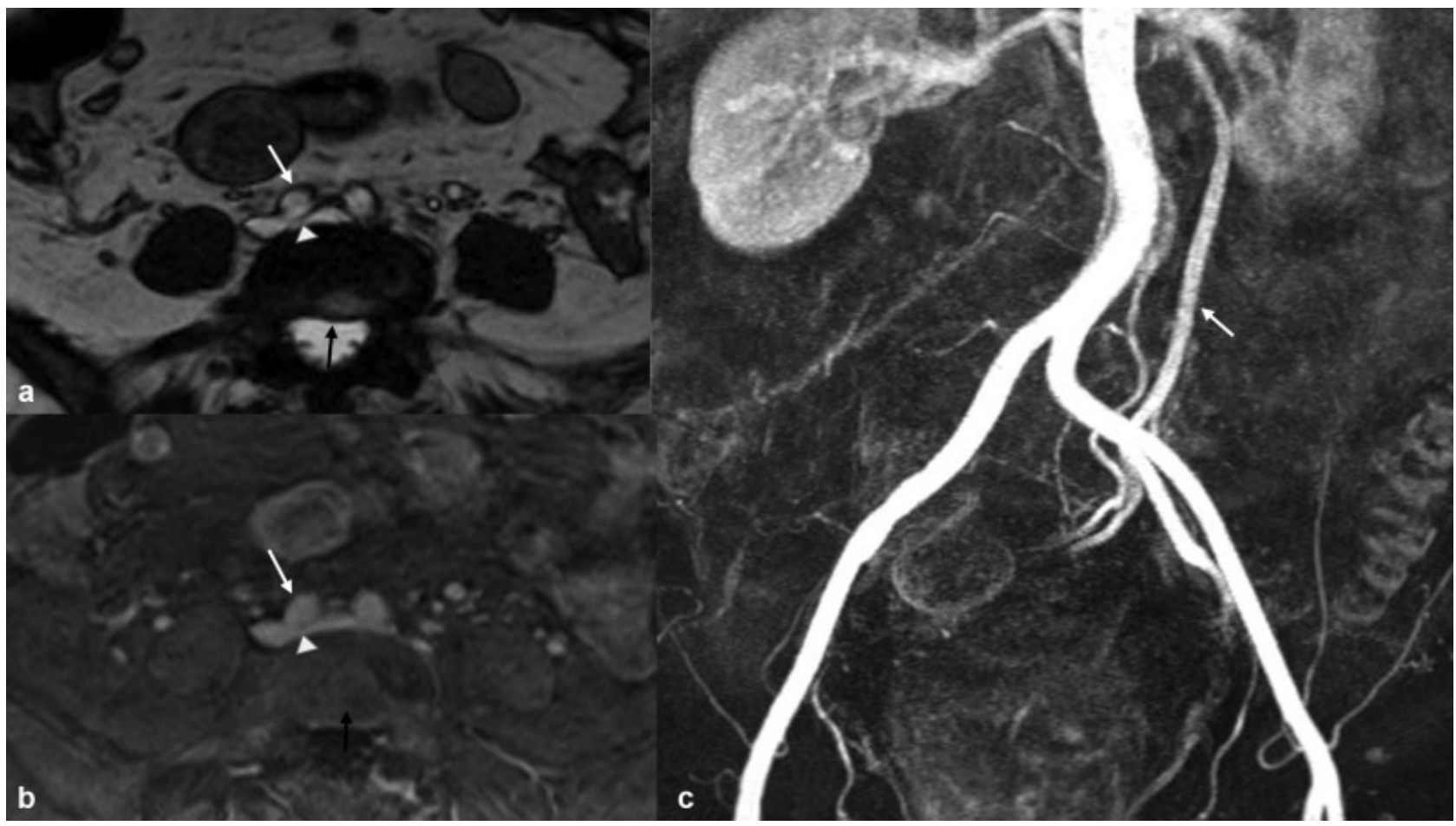

Fig. 4 Imágenes de ARM (a) T2 True Fast Imaging (TRUFI) axial y (b) T1 Volumetric Interpolated Breath Hold Examination (VIBE) axial, donde se observa compresión de la vena ilíaca común izquierda (cabeza de flecha), con disminución del calibre en su trayecto entre la arteria ilíaca común derecha (flecha blanca) y la columna lumbar inferior (flecha negra). (c) Reconstrucciones de Proyección de Máxima Intensidad (MIP). con evidencia de desarrollo de circulación colateral (flecha blanca).

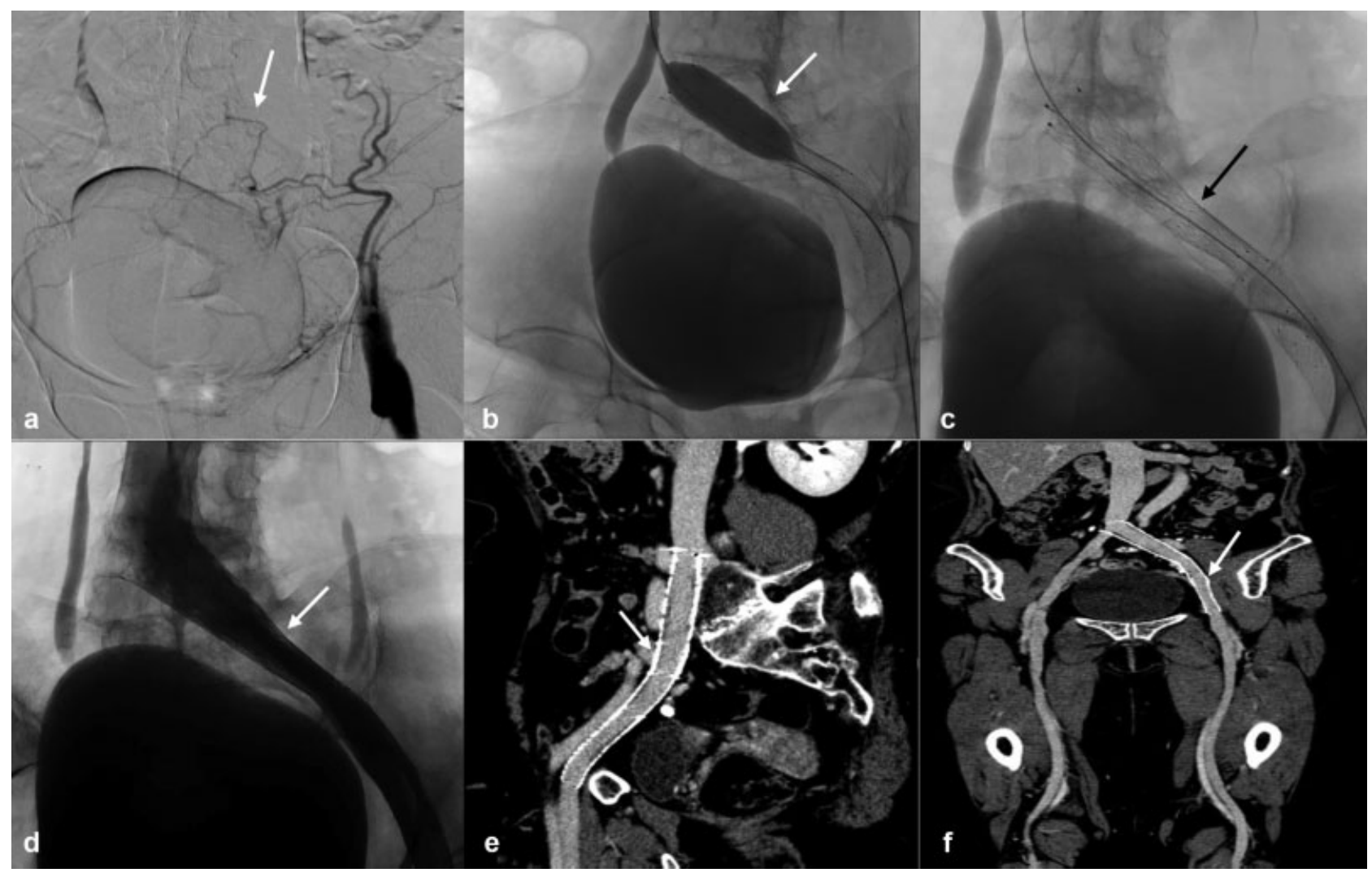

Fig. 5 (a) Imagen de angiografía que muestra una oclusión completa del eje venoso iliaco izquierdo (flecha blanca). (b) y (c) Tromboaspiración y angioplastia con balón (flecha blanca) de vena ilíaca primitiva y tercio distal de la misma, más colocación de stents (flecha negra) cubriendo la totalidad del eje iliaco. (d) Control angiográfico final muestra permeabilidad de todo el eje ilíaco venoso izquierdo sin áreas de estenosis residual (flecha blanca). (e) y (f) Control con flebografía por tomografía computarizada a los seis meses post procedimiento, donde se evidencia endoprótesis que cubre la totalidad de la vena ilíaca primitiva e ilíaca externa izquierda permeable, de calibre conservado (flecha blanca). 


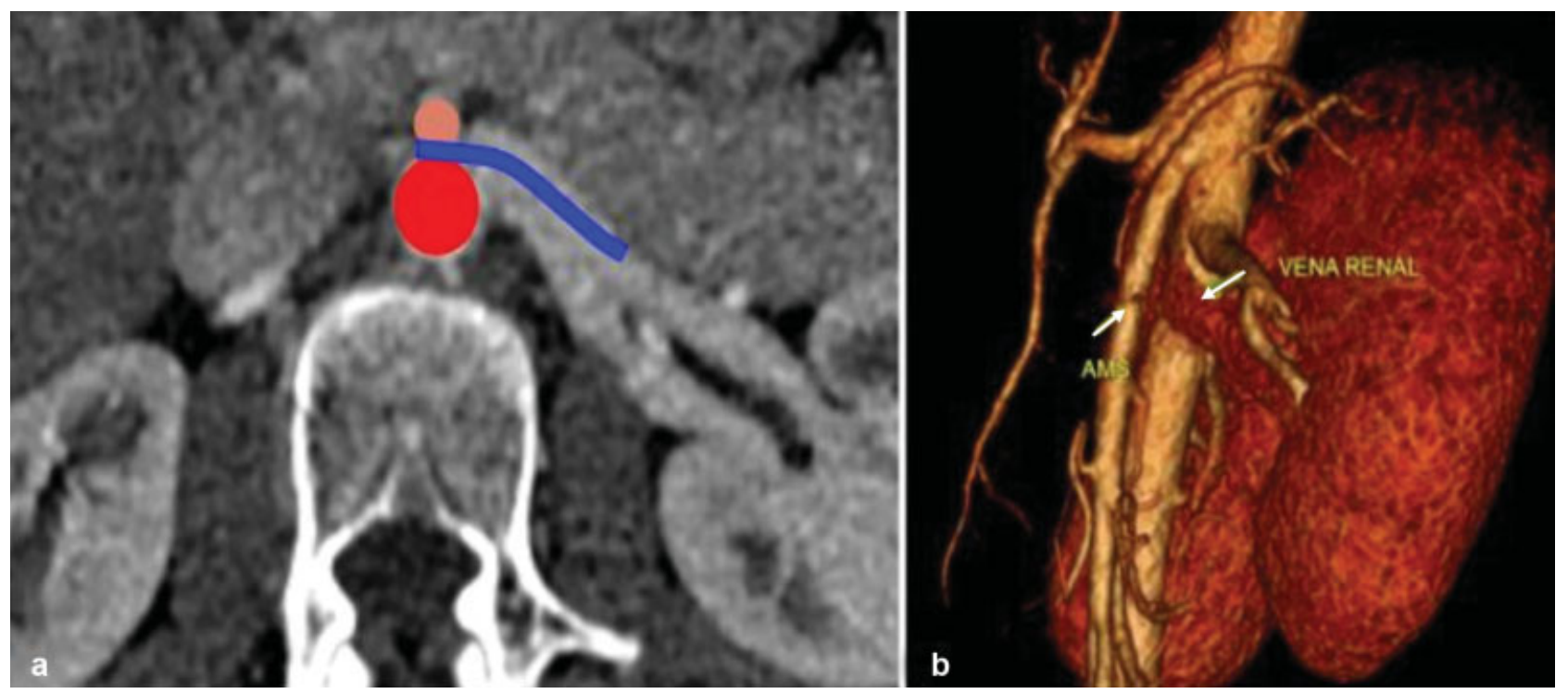

Fig. 6 (a) ATC de abdomen en corte axial con visualización de la compresión de la vena renal izquierda (línea azul) entre la aorta (punto rojo) y la arteria mesentérica superior (punto rosado). (b) Reconstrucción en 3D.

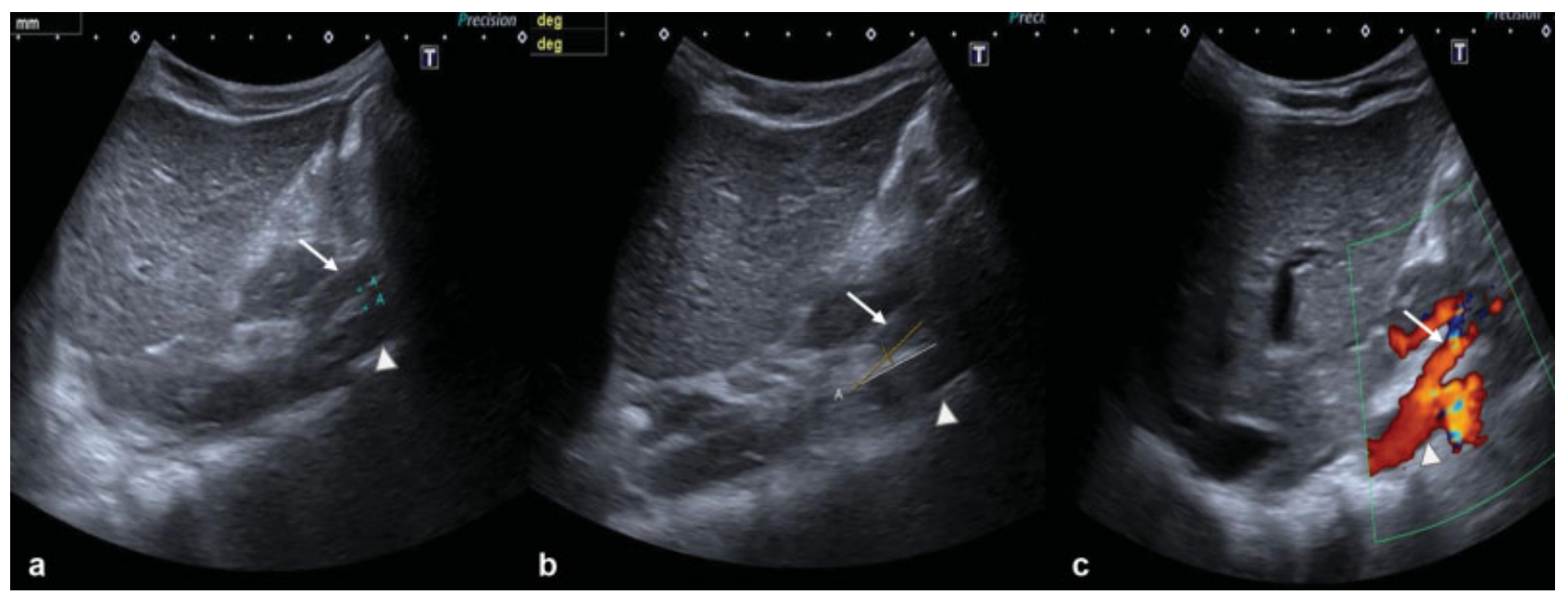

Fig. 7 Paciente masculino de nueve años en estudio por dolor abdominal y hematuria, al cual se le realiza ultrasonografía Doppler abdominal. (a) Muestra la distancia entre pared posterior de la arteria mesentérica (flecha blanca), superior y pared anterior de la aorta abdominal (cabeza de flecha) es de 6,7 mm (normal > $10 \mathrm{~mm}$ ); (b) y (c) y el ángulo aorto-mesentérico, que es de $16^{\circ}$ (flecha blanca) (normal $>$ a $25^{\circ}$ ).

El diagnóstico se realiza mediante la evaluación clínica, los hallazgos de laboratorio y la confirmación mediante estudios de imágenes. Esa enfermedad se presenta usualmente entre la segunda y tercera década de la vida, con una ligera predisposición en mujeres. Los signos y síntomas más comunes son hematuria (78\%), dolor en flanco izquierdo (38\%), varicocele (35\%), proteinuria (30\%) y anemia (13\%). ${ }^{13,14}$

De los estudios imagenológicos, la ultrasonografía Doppler suele ser el método diagnóstico inicial. Entre los hallazgos más relevantes encontramos un ángulo entre la aorta abdominal y la AMS $<25^{\circ}$ (normal $51 \pm 25^{\circ}$ ), una distancia entre la aorta abdominal y la AMS $<10 \mathrm{~mm}$ (normal $16 \pm 6 \mathrm{~mm}$ ), tiempo de aceleración en el sitio de estenosis $>100 \mathrm{~cm} / \mathrm{s}$, la relación del diámetro interno entre el hilio renal y la estenosis de la VRI en posición supina $>$ a 3 veces y de pie (posterior a 15 minutos) $>5$. Esos hallazgos tienen una sensibilidad del 78\% y una especificidad cercana al 100\% para el diagnóstico (-Fig. 7) ${ }^{14-16}$

En cuanto a la ATC, el hallazgo característico es el adelgazamiento abrupto de la VRI con una configuración triangular en la porción aorto/mesentérica conocido como "The beak sign", con una sensibilidad del $91 \%$ y una especificidad del $88,9 \%$. Tanto la ATC como la ARM son útiles para determinar el ángulo entre la VMS y la aorta. Asimismo, el desarrollo de vasos colaterales (- Figs. 8 y 9). De los métodos invasivos, la venografía permite medir el gradiente de presión entre la vena cava inferior y la VRI, con valor diagnóstico $>2 \mathrm{~mm} \mathrm{Hg}^{16}$

El tratamiento de un paciente sintomático, se realiza mediante la colocación endovascular de un stent en la vena renal, procedimiento que tiene un alto porcentaje de éxito. Existen otros procedimientos quirúrgicos invasivos, como la transposición de la vena renal, transposición de la arteria 

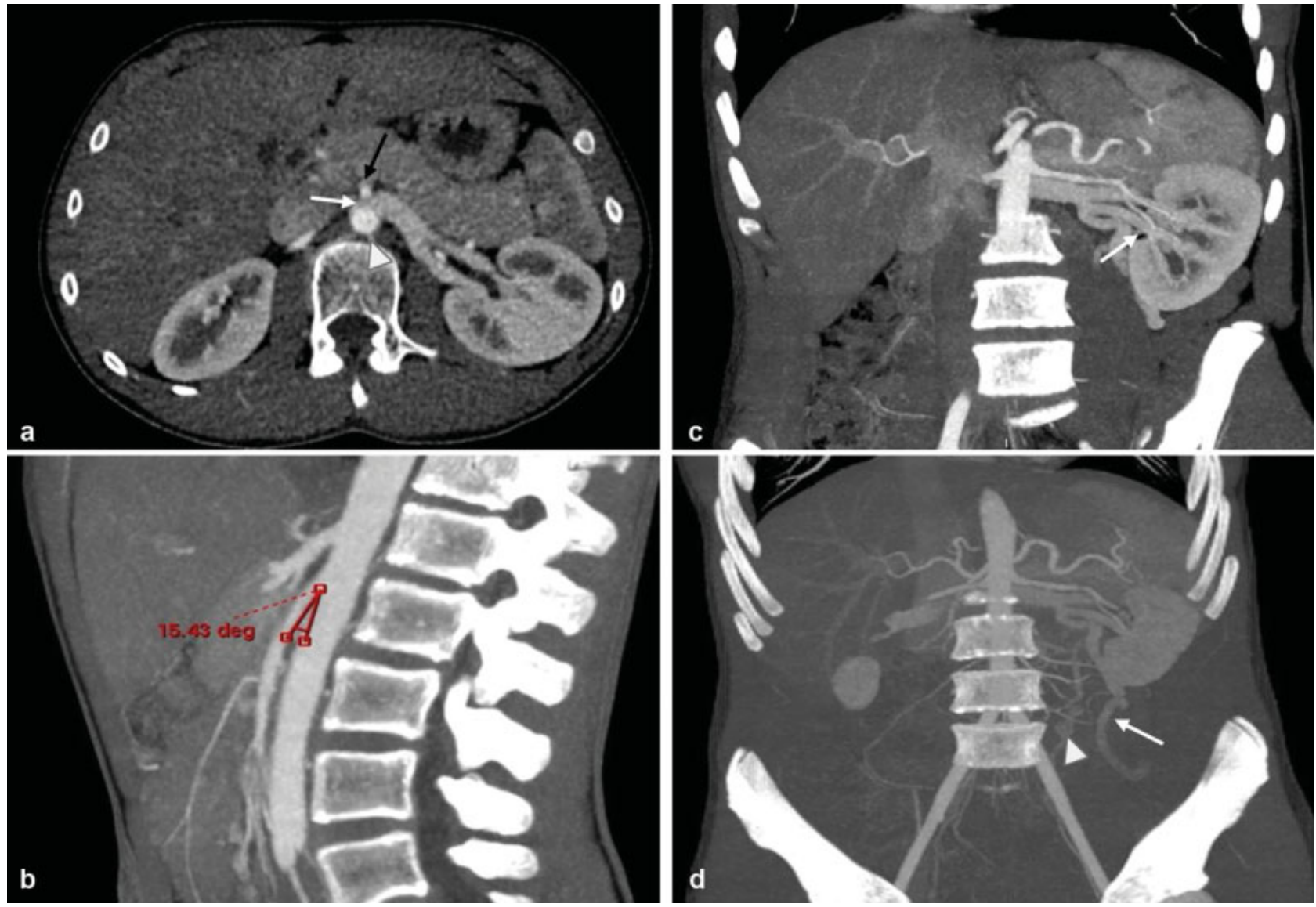

Fig. 8 ATC con reconstrucciones MIP. (a) Se observa compresión significativa de la vena renal izquierda (flecha blanca) entre la aorta abdominal (cabeza de flecha) y la arteria mesentérica superior (flecha negra). (b) El ángulo del compás aortomesentérico es de 15 grados. (c) Asocia dilatación retrógrada de vasos venosos a nivel de la pelvis renal (flecha). (d) Vena gonadal (flecha blanca) de 7 mm y apertura de colaterales (cabeza de flecha), que discurren en paralelo a la vena gonadal.

mesentérica superior, autotransplante renal y bypass gonadal (-Fig. 10). ${ }^{16}$

\section{Síndrome de opérculo torácico}

El síndrome de opérculo torácico se define como el atrapamiento del plexo braquial, la arteria o vena subclavia en el compartimento torácico que está comprendido entre la columna cervical y mediastino hasta el borde inferior del músculo pectoral menor, conocido como "salida torácica."17 Anatómicamente, la salida torácica se compone de tres espacios fundamentales: el triángulo interescaleno, el espacio costo-clavicular (canal cervicoaxilar) y el espacio retropectoral menor (-Fig. 11). ${ }^{18}$

Clínicamente se ha dividido en dos grandes categorías, de acuerdo a si presenta un compromiso neurológico o vascular, siendo en el 95\% de los casos neurológico. Sin embargo, pueden manifestarse ambas entidades al mismo tiempo. ${ }^{2-18}$ Los síntomas neurológicos pueden ser sensitivos (parestesias o dolor) y/o motores. Cuando se presenta por compresión arterial los síntomas son dolor, parestesias, frialdad y alteración en la temperatura (poiquilotermia). Si el compromiso es venoso los síntomas son dolor, edema y cianosis. Si el compromiso es crónico puede verse desarrollo de vasos colaterales. ${ }^{18}$
Posterior a la evaluación y test clínicos, los estudios por imágenes son importantes para el diagnóstico de certeza. El primer método que se realiza es la radiografía, la cual permite visualizar anormalidades anatómicas como causa subyacente. Las más comunes son las costillas cervicales, proceso transverso elongado de C7 y anormalidades de la primera costilla. ${ }^{19}$

La ultrasonografía Doppler color, permite realizar un estudio dinámico (paciente sentado, de pie, con el brazo elevado). En la evaluación de los vasos axilo-subclavios, los hallazgos que sugieren obstrucción son el aumento de la ecogenicidad del lumen vascular, la ausencia de señal Doppler y la no compresibilidad. Otros hallazgos que pueden verse son el desarrollo de colaterales (trombosis crónica). Como limitante del método se tiene la pobre visualización de la vena subclavia, por lo que la utilidad es principalmente en el compromiso vascular de etiología arterial. $^{19}$

La ATC es un método de gran utilidad porque permite la valoración de anormalidades anatómicas y vasculares. El estudio se realiza con material de contraste endovenoso iodado, el cual se administra en el brazo sano, con cambios dinámicos de ambas extremidades superiores (abducción y aducción), tanto en una fase arterial como venosa. La adquisición se realiza desde la mitad del pecho hasta el codo del brazo en abducción. La ARM es otro método que 

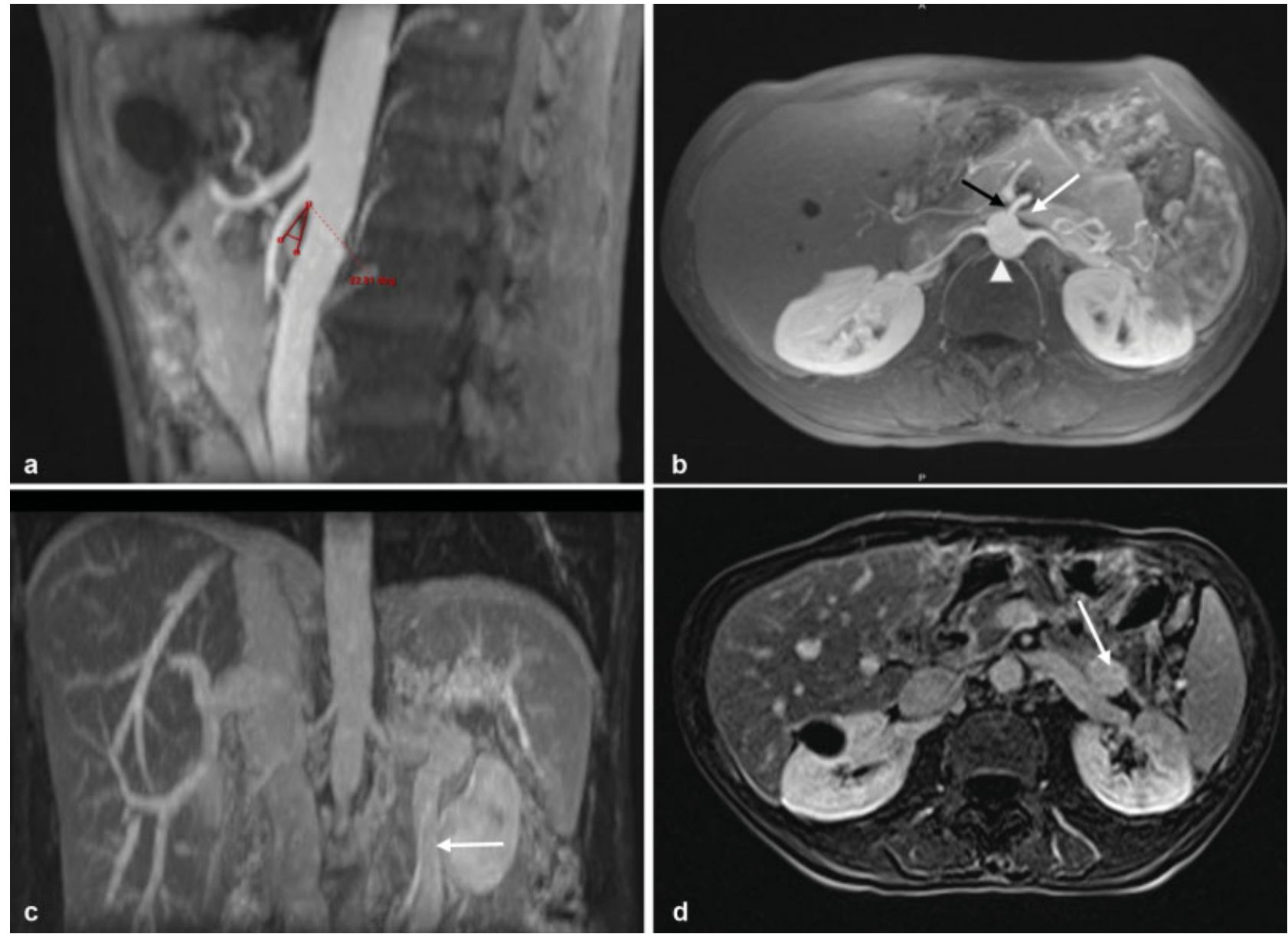

Fig. 9 Imágenes de ARM. (a) T1 VIBE sagital y (b) T1 VIBE axial en reconstrucción MIP, donde se observa disminución del ángulo aorto/mesentérico asociado a compresión de la vena renal izquierda (flecha blanca) entre la aorta abdominal (cabeza de flecha) y la AMS (flecha negra). (c) T1 VIBE coronal y (d) axial, reconstrucciones MIP donde se asocia dilatación retrógrada de la vena gonadal (flecha blanca).
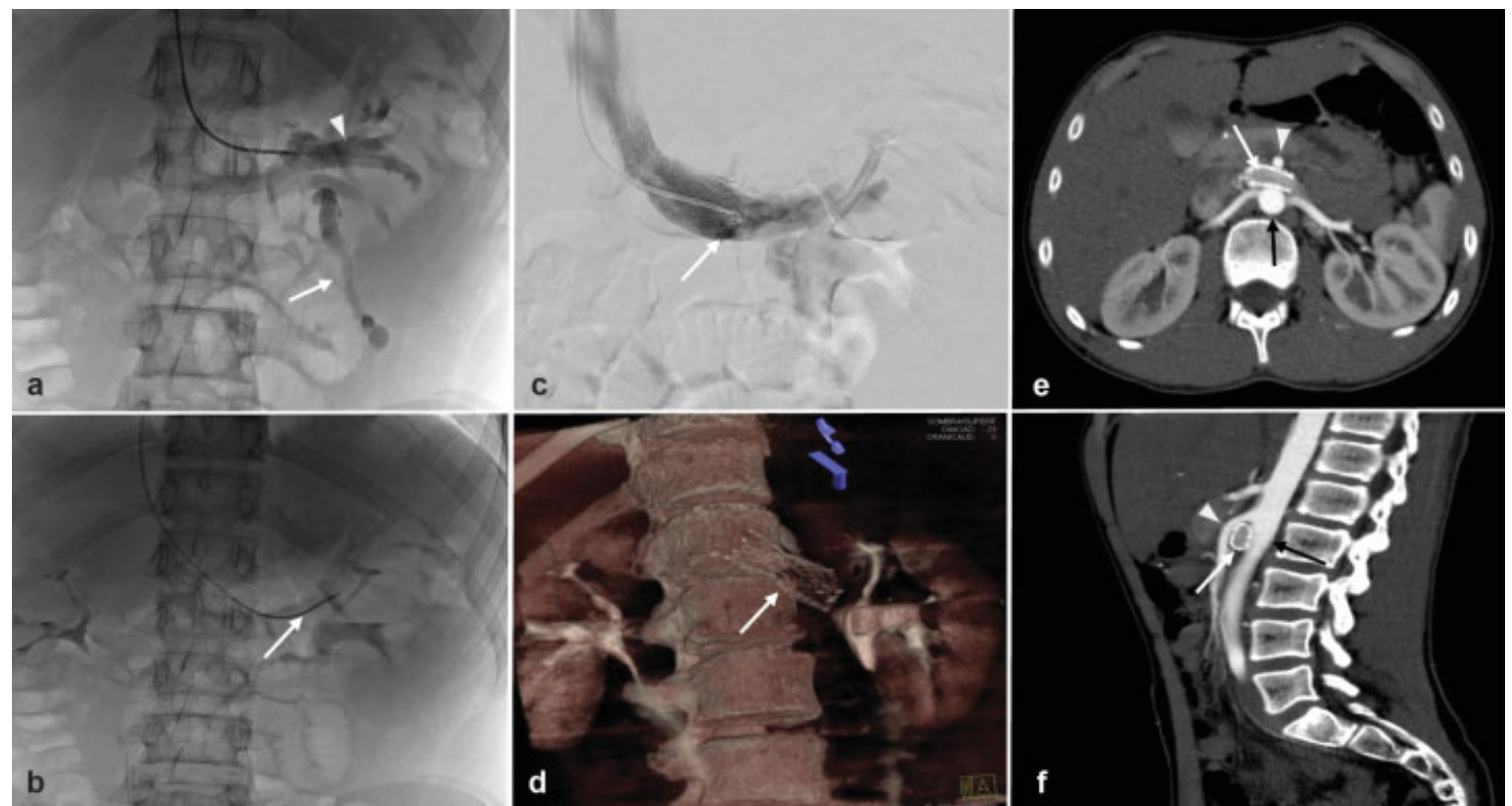

Fig. 10 Angiografía más angioplastia de la vena renal. (a) Catéter tipo multipropósito con el cual se cateteriza la vena renal izquierda, que muestra compresión proximal de la misma, asociada a inversión del flujo en la vena gonadal (flecha blanca) y ectasia en venas intrarenales (cabeza de flecha). (b) y (c) Se evidencia liberación de stent en la vena renal previo a la desembocadura de la vena gonadal y protruyendo levemente en la $\mathrm{VCl}$ (flecha blanca), cubriendo la compresión generada por el compás aorto/mesentérico (d) ATC reconstrucción en 3D. (e) y (f) Control tomográfico, donde se observa stent en vena renal izquierda permeable (flecha blanca) entre la aorta abdominal (flecha negra) a la AMS (cabeza de flecha). 


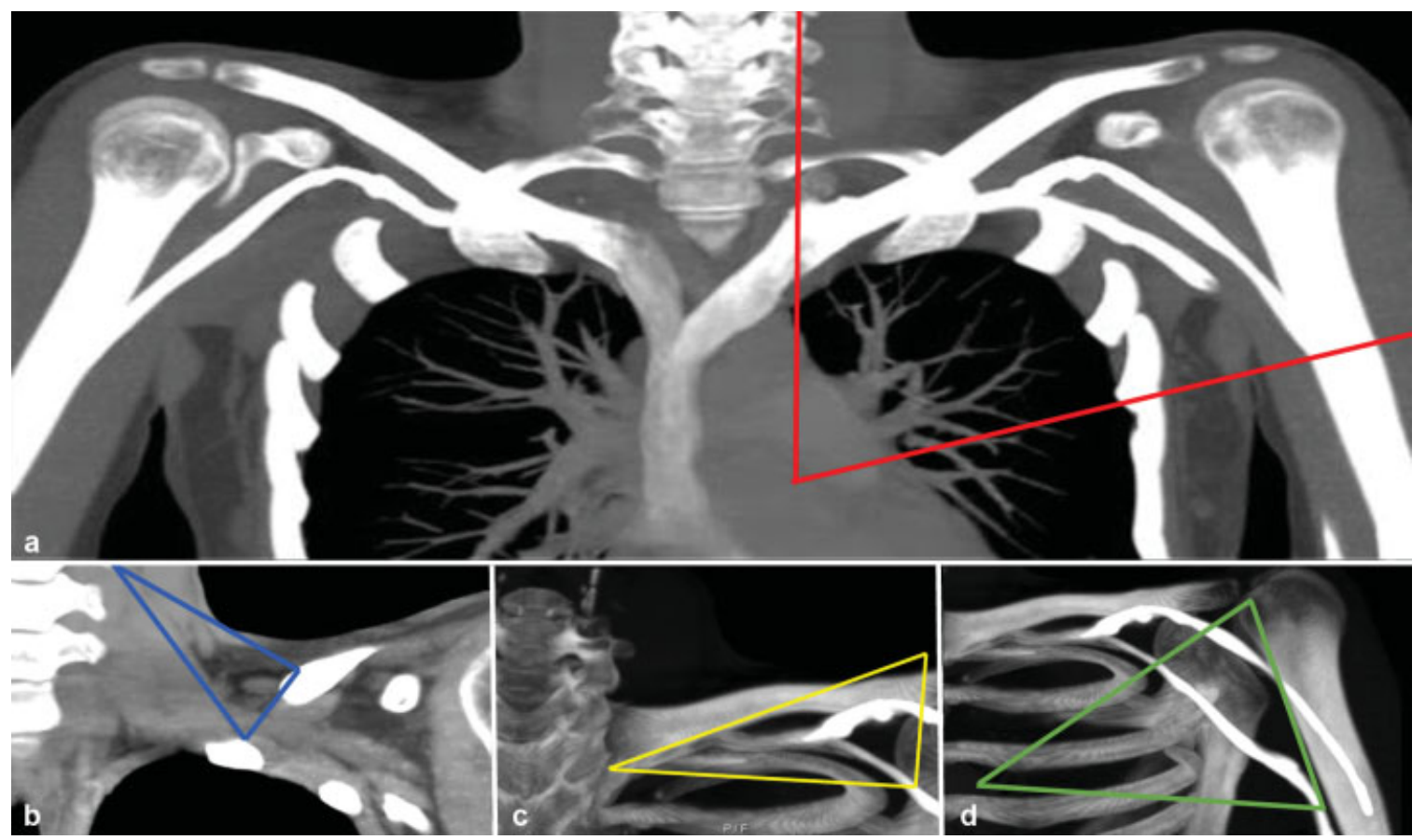

Fig. 11 (a) El opérculo torácico es el compartimento comprendido entre la columna cervical y mediastino hasta el borde inferior del músculo pectoral menor (triángulo rojo). (b) Triángulo interescaleno (triángulo azul), (c) el espacio costo-clavicular (canal cervicoaxilar) (triángulo amarillo) y D) y el espacio retropectoral menor (triángulo verde).

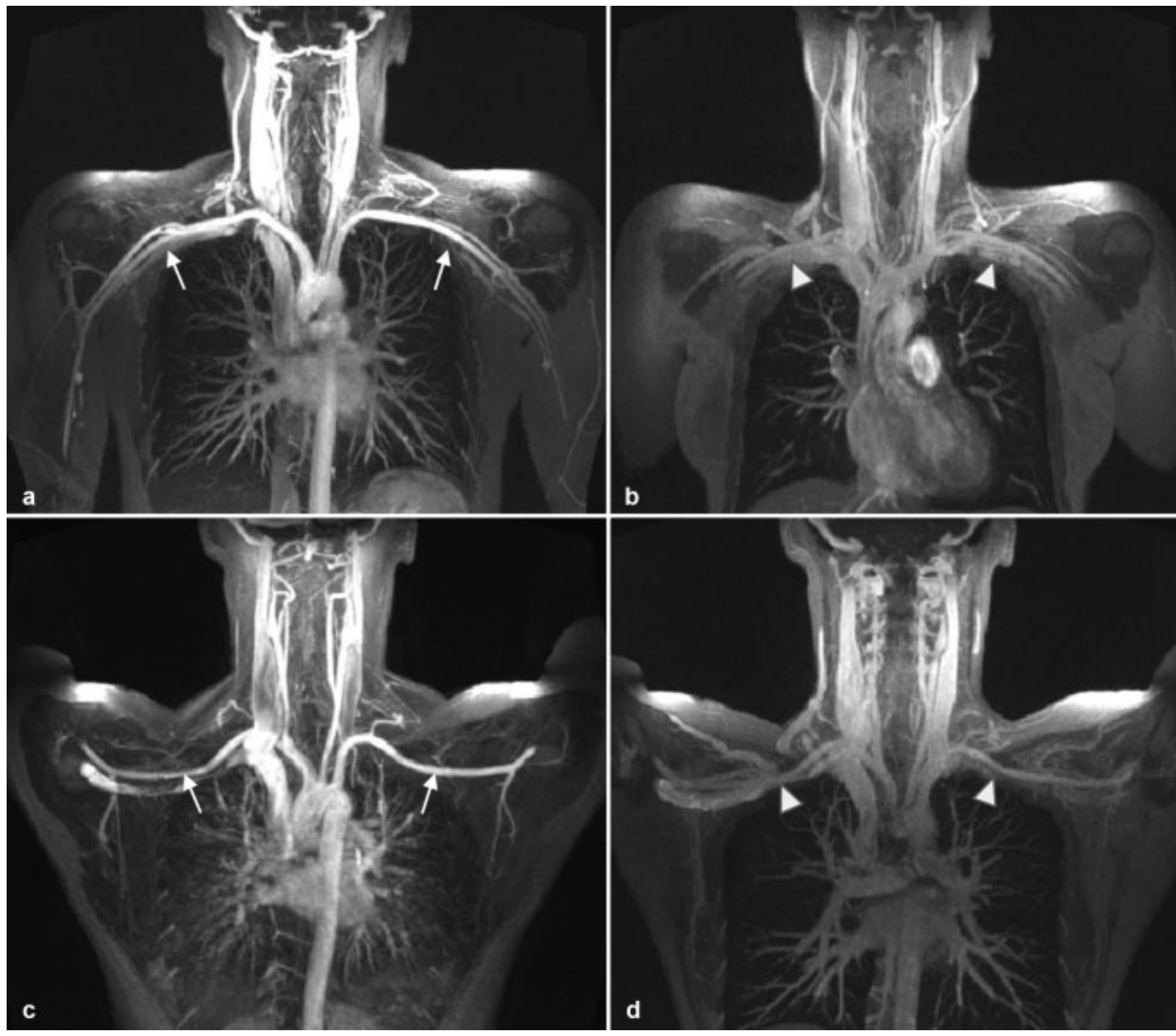

Fig. 12 Imágenes de ARM de tórax ponderadas en T1 VIBE coronal con reconstrucciones MIP en tiempo arterial (flecha blanca) (a) y venoso (cabeza de flecha) (b) con maniobras en reposo (c) y en extensión (d) (protocolo de opérculo torácico). 

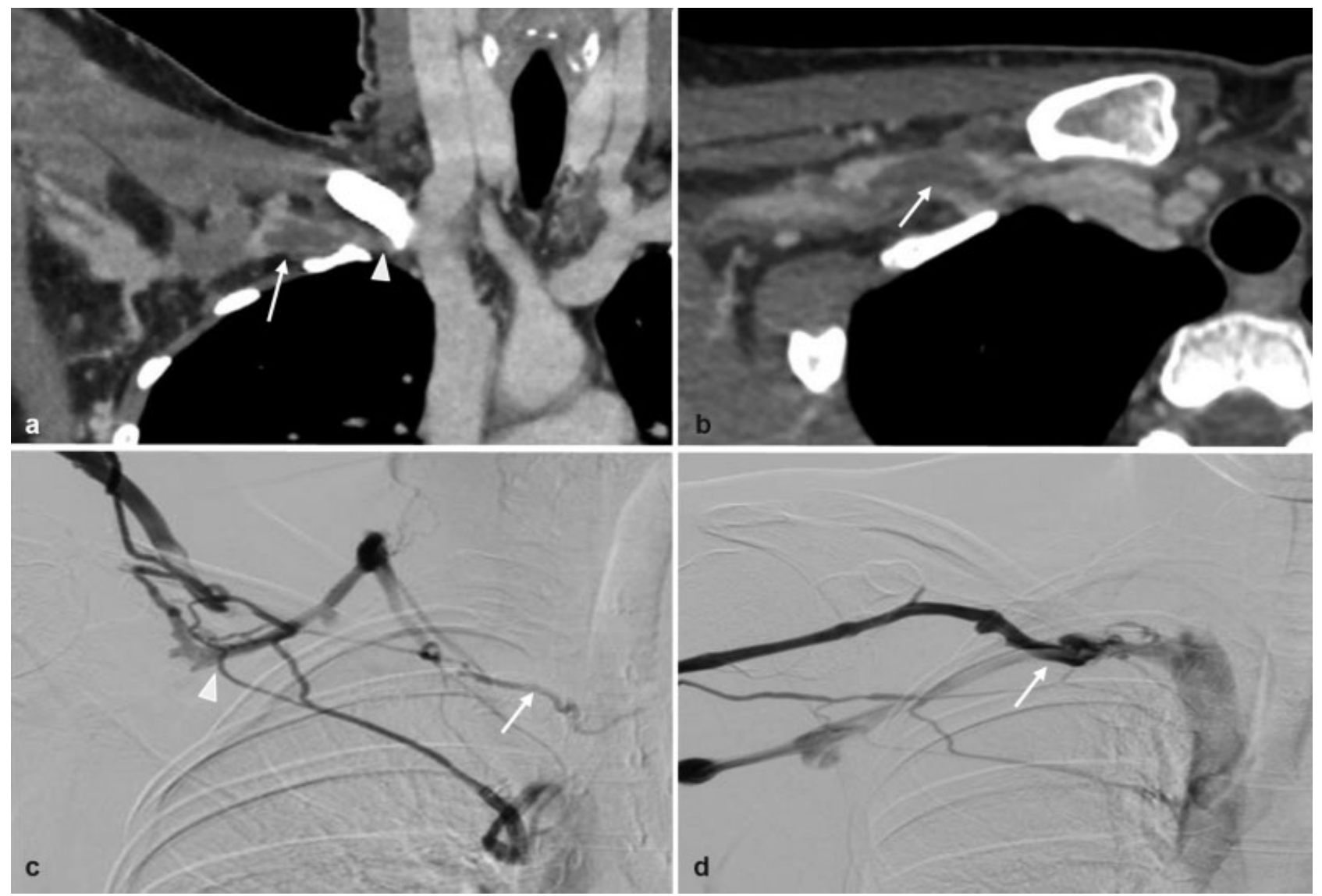

Fig. 13 ATC de tórax en corte coronal (a) y axial (b) con visualización de trombosis oclusiva de vena subclavia derecha (flecha blanca), con reducción del tamaño del espacio costoclavicular (cabeza de flecha). Flebografía en maniobra de hiperextensión (c) con evidencia de zona de disminución de flujo de la vena subclavia derecha (flecha blanca) y circulación colateral en la región del hombro ipsilateral (cabeza de flecha). Reposo (d) con mejoría en circulación de vena subclavia homolateral (flecha blanca).

se utiliza para el diagnóstico, realizando secuencias en fase arterial y venosa con los brazos en abducción y aducción (-Fig. 12) $\cdot^{19}$

Los hallazgos en el compromiso venoso son áreas de trombosis, sitios de adelgazamiento vascular y desarrollo de vasos colaterales (cronicidad) ( - Fig. 13). En el compromiso arterial se incluyen la visualización de aneurisma o pseudoaneurismas, asociado o no a trombosis arterial, al igual que vasos colaterales. En los casos de compromiso neurogénico, la ARM puede mostrar signos de espondilosis cervical severa, plexitis y anormalidades óseas y/o musculares. ${ }^{19,20}$

Después de realizar el diagnóstico, el tratamiento se indica en los pacientes sintomáticos. En los casos por compresión neurogénica, puede realizarse un manejo conservador con terapia física. En los casos en que no mejora con terapia física o si presentan un compromiso vascular, se pueden realizar múltiples procedimientos quirúrgicos y/o endovasculares, los cuales dependen de la causa subyacente. ${ }^{21}$

\section{Conclusiones}

Los estudios por imágenes constituyen herramientas fundamentales para el diagnóstico, planificación terapéutica y seguimiento de los síndromes compresivos vasculares.
Dentro de ellos, la ultrasonografía Doppler resulta útil como método inicial debido a su fácil accesibilidad y a la ausencia de radiación, factor fundamental ya que en su mayoría se trata de pacientes jóvenes en edad fértil. Por su parte, la ATC y la ARM, con sus reconstrucciones multiplanares, cumplen un rol fundamental en el diagnóstico y tratamiento, ya que permiten visualizar el sitio de compresión, la causa y la extensión de la misma, como así también del seguimiento.

\section{Confidencialidad de los Datos}

Los autores declaran que han seguido los protocolos de su centro de trabajo sobre la publicación de datos de pacientes, y que todos los pacientes incluidos en el estudio, han recibido información suficiente y han dado su consentimiento informado por escrito.

\section{Conflicto de Intereses}

Los autores declaran no tener ningún conflicto de intereses.

\section{Bibliografía}

1 Eliahou R, Sosna J, Bloom AI. Between a rock and a hard place: clinical and imaging features of vascular compression syndromes. Radiographics 2012;32(01):E33-E49. Doi: 10.1148/rg.321115011 
2 Demondion X, Herbinet P, Van Sint Jan S, Boutry N, Chantelot C, Cotten A. Imaging assessment of thoracic outlet syndrome. Radiographics 2006;26(06):1735-1750. Doi: 10.1148/rg.266055079

3 Lugo-Fagundo C, Nance JW, Johnson PT, Fishman EK. May-Thurner syndrome: MDCT findings and clinical correlates. Abdom Radiol (NY) 2016;41(10):2026-2030. Doi: 10.1007/s00261-016-0793-9

4 Kibbe MR, Ujiki M, Goodwin AL, Eskandari M, Yao J, Matsumura J. Iliac vein compression in an asymptomatic patient population. J Vasc Surg 2004;39(05):937-943. Doi: 10.1016/j.jvs.2003.12.032

5 Zander KD, Staat B, Galan H. May-Thurner Syndrome resulting in acute iliofemoral deep vein thrombosis in the postpartum period. Obstet Gynecol 2008;111(2 Pt 2):565-569. Doi: 10.1097/01. AOG.0000299875.19865.4c

6 Murphy EH, Davis CM, Journeycake JM, DeMuth RP, Arko FR. Symptomatic ileofemoral DVT after onset of oral contraceptive use in women with previously undiagnosed May-Thurner Syndrome. J Vasc Surg 2009;49(03):697-703. Doi: 10.1016/j.jvs.2008.10.002

7 Oteros Fernández R, Bravo Rodríguez F, Delgado Acosta F, González Barrios I. [May-Thurner syndrome and surgery for scoliosis]. Radiologia (Madr) 2008;50(03):245. Doi: 10.1016/ S0033-8338(08)71971-4

8 Sulzdorf L. May-Thurner Syndrome Presenting With Venous Claudication. A Common Sequela of Iliofemoral Thrombosis. JDMS 2006;22:243-252. Doi: 10.1177/8756479306289339

9 Brinegar KN, Sheth RA, Khademhosseini A, Bautista J, Oklu R. Iliac vein compression syndrome: Clinical, imaging and pathologic findings. World J Radiol 2015;7(11):375-381. Doi: 10.4329/wjr.v7.i11.375

10 Zucker EJ, Ganguli S, Ghoshhajra BB, Gupta R, Prabhakar AM. Imaging of venous compression syndromes. Cardiovasc Diagn Ther 2016;6(06):519-532. Doi: 10.21037/cdt.2016.11.19

11 Ou-Yang L, Lu GM. Underlying Anatomy and Typing Diagnosis of May-Thurner Syndrome and Clinical Significance: An Observation Based on CT. Spine 2016;41(21):E1284-E1291. Doi: 10.1097/ BRS.0000000000001765
12 Pulgarin Ricardo LG, Isaza Zapata S, Uribe Gonzalez R. Left inferior vena cava with nutcracker syndrome: A case report. Radiol Case Rep 2017;13(01):32-34. Doi: 10.1016/j.radcr.2017.10.007

13 Orczyk K, Wysiadecki G, Majos A, Stefańczyk L, Topol M, Polguj M. What Each Clinical Anatomist Has to Know about Left Renal Vein Entrapment Syndrome (Nutcracker Syndrome): A Review of the Most Important Findings. BioMed Res Int 2017;2017:1746570. Doi: $10.1155 / 2017 / 1746570$

14 Gulleroglu K, Gulleroglu B, Baskin E. Nutcracker syndrome. World J Nephrol 2014;3(04):277-281. Doi: 10.5527/wjn.v3.i4.277

15 Venkatachalam S, Bumpus K, Kapadia SR, Gray B, Lyden S, Shishehbor MH. The nutcracker syndrome. Ann Vasc Surg 2011; 25(08):1154-1164. Doi: 10.1016/j.avsg.2011.01.002

16 Al-Katib S, Shetty M, Jafri SM, Jafri SZ. Radiologic Assessment of Native Renal Vasculature: A Multimodality Review. Radiographics 2017;37(01):136-156. Doi: 10.1148/rg.2017160060

17 Ersoy H, Steigner ML, Coyner KB, et al. Vascular thoracic outlet syndrome: protocol design and diagnostic value of contrastenhanced 3D MR angiography and equilibrium phase imaging on 1.5- and 3-T MRI scanners. AJR Am J Roentgenol 2012;198(05): 1180-1187. Doi: 10.2214/AJR.11.6417

18 Klaassen Z, Sorenson E, Tubbs RS, et al. Thoracic outlet syndrome: a neurological and vascular disorder. Clin Anat 2014;27(05): 724-732. Doi: 10.1002/ca.22271

19 Raptis CA, Sridhar S, Thompson RW, Fowler KJ, Bhalla S. Imaging of the Patient with Thoracic Outlet Syndrome. Radiographics 2016;36(04):984-1000. Doi: 10.1148/rg.2016150221

20 Aralasmak A, Cevikol C, Karaali K, et al. MRI findings in thoracic outlet syndrome. Skeletal Radiol 2012;41(11):1365-1374. Doi: 10.1007/s00256-012-1485-3

21 Laulan J, Fouquet B, Rodaix C, Jauffret P, Roquelaure Y, Descatha A. Thoracic outlet syndrome: definition, aetiological factors, diagnosis, management and occupational impact. J Occup Rehabil 2011;21(03):366-373. Doi: 10.1007/s10926-010-9278-9 